\title{
Dairy cattle mortality in an organized herd in Bangladesh
}

\author{
M. M. Hossain ${ }^{1,2}$, M. S. Islam ${ }^{1,3}$, A. H. M. Kamal ${ }^{2}$, A. K. M. A. Rahman ${ }^{4}$ and H. S. Cho ${ }^{1}$ \\ 1. College of Veterinary Medicine, Chonbuk National University, Jeonju, Republic of Korea; \\ 2. Department of Medicine, Sylhet Agricultural University, Sylhet, Bangladesh; \\ 3. Department of Medicine, Surgery and Obstatrics, Hajee Mohammad Danesh Science and Technology University, \\ Dinajpur, Bangladesh; 4. Department of Medicine, Bangladesh Agricultural University, Mymensingh, Bangladesh \\ Corresponding author: M. M. Hossain, email: mukter.sau@gmail.com \\ Received: 17-03-2014, Revised: 10-04-2014, Accepted: 16-04-2014, Published online: 19-05-2014
}

doi: $10.14202 /$ vetworld.2014.331-336

How to cite this article: Hossain MM, Islam MS, Kamal AHM, Rahman AKMA and Cho HS (2014) Dairy cattle mortality in an organized herd in Bangladesh, Veterinary World 7(5): 331-336.

\begin{abstract}
Aim: The present study was conducted to find out the causes and factors affecting the dairy cattle mortality.

Materials and Methods: A retrospective study of dairy cattle mortality on the Central Cattle Breeding and Dairy Farm (CCBDF) in Bangladesh was carried out between 1992 and 2007. Sixteen years of data on mortality of dairy cattle were analyzed for the effects of year, season, age, sex, breed, and etiology on mortality rate.

Results: The average overall mortality rate was $5.60 \%$ and on average, female cattle $(55.71 \%)$ were found to die more than males (44.29\%). Mortality was more in crossbred cattle than in indigenous breed. Higher mortality of cattle was observed in rainy season (37.98\%) followed by winter (33.03\%) and summer (28.99\%). The major causes of death were diseases of the respiratory tract, mainly pneumonia (39.91\%). Tuberculosis was the second most common cause of mortality accounting for $20.58 \%$ of deaths. The other major cause of death was disease of the alimentary tract, mainly enteritis (15.58\%). Other causes of death occurred in the following frequencies: malnutrition (5.91\%), debility (4.43\%), hairball (3.35\%), tympanitis (2.56\%), babesiosis (2.27\%), internal haemorrhage (2.16\%), black quarter (1.76\%), and foot and mouth disease (1.48\%).
\end{abstract}

Conclusions: Of the four potential risk factors investigated, age was the most important factor and significantly associated with mortality. During the first month of life, calves had a higher risk of mortality than adults.

Keywords: Bangladesh, dairy cattle, mortality.

\section{Introduction}

Dairy cattle mortality is a severe problem for the dairy industry. Mortality has been steadily increasing during the last 2 decades all over the world [1]. The mortality rate increased from 2.6 to $5.7 \%$ in the United States from 1996 to 2007 [2], and in Ireland from 3.3 to $4.4 \%$ between 2002 and 2006 [3]. Shaikh [4] conducted a study on morbidity and mortality in cattle covering four regions of Maharashtra and reported that the overall morbidity and mortality rate in cattle was $19.22 \%$ \& $12.48 \%$, respectively. Mortality among dairy cattle results in financial loss, including the value of the lost cattle, cost of replacement, loss of milk production, and extra labor [5]. Therefore, it constitutes a problem of animal welfare and farm economy. Several herd-level risk factors for mortality have been identified, such as herd size, herd management, SCC and milk yield [5-7]. Mortality patterns in organized dairy herds serve as a useful indicator for assessing the status of herd health and the efficacy of management programs [8]. A rise in mortality among a group of cattle can indicate suboptimal health and welfare [9]. Bangladesh is a densely populated country with an agricultural-based economy and its livestock play an important role. Agricultural

Copyright: The authors. This article is an open access article licensed under the terms of the Creative Commons Attribution License (http://creativecommons.org/licenses/by/2.0) which permits unrestricted use, distribution and reproduction in any medium, provided the work is properly cited. livestock account for about $6.5 \%$ of total income and about $25 \%$ of the country's population are directly involved in this sector. Dairy industry is a crucial component of an agro-based economy for a country like Bangladesh [10]. Inadequate feeding, widespread disease, and inefficient extension services are considered among the most binding constraints on livestock development in Bangladesh.

The Directorate of Livestock Services (DLS), Government of Bangladesh has established a Central Cattle Breeding and Dairy Farm (CCBDF) at Savar, Dhaka to meet the excessive demands for milk, particularly for the capital city. The success of the CCBDF partly depends on sound health management of the animals and efficient production techniques. However, diseases are one of the major health constraints for livestock development in Bangladesh. Calf mortality in every dairy and breeding farm results in financial and genetic loss. Cattle mortality was shown to be the major cause of economic losses on a dairy farm in Bangladesh [11]. Therefore, reductions in morbidity and mortality rate are the first and foremost targets of dairy farm management [8].

Identification of factors that are responsible for the death of cattle is an important prerequisite for avoiding excessive mortality. An epidemiological approach usually involves collecting and evaluating pre-existing data to find associations with the problem. 


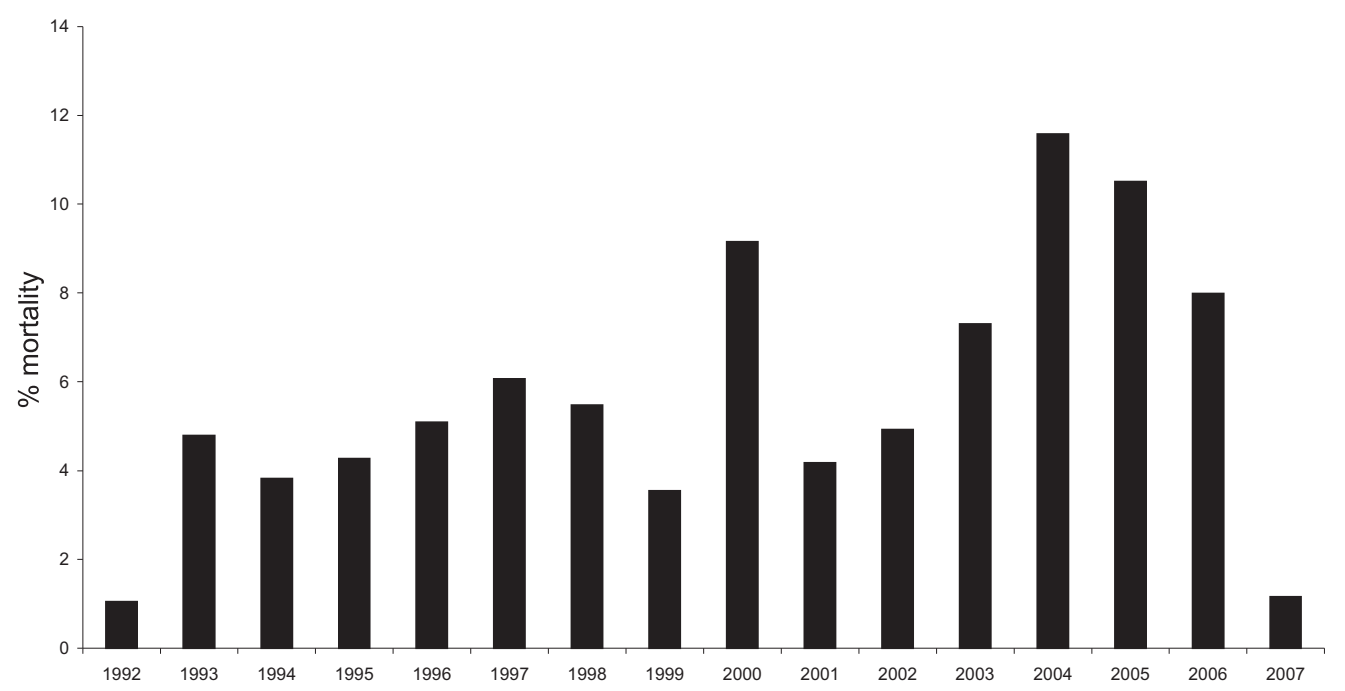

Figure-1: Annual mortality rates by year for dairy cattle on the CCBDF, Savar, Bangladesh (1992-2007).

Therefore, the present study was conducted to find out the causes and factors affecting the dairy cattle mortality on CCBDF

\section{Materials and Methods}

Study site: The study was conducted at the CCBDF at Savar, Dhaka, Bangladesh. The CCBDF was established in 1973 on 1300 acres of land with the assistance of the German Agency for Technical Cooperation at Savar Upazila in the Dhaka district of Bangladesh. This farm is located between $23^{\circ} 46^{\prime}$ and $23^{\circ} 58^{\prime}$ North latitude and $90^{\circ} 12^{\prime}$ and $90^{\circ} 20^{\prime}$ East longitude and about $30 \mathrm{~km}$ northwest of the capital city of Dhaka.

Nature and source of data: For the retrospective study, the data were collected based on farm records of all cattle deaths over a period of 16 years (1992 to 2007) on the CCBDF. Information on the date of birth, sex, breed, date of death, and causes of death were collected from the farm at the individual animal level. The age and breed of cattle were collected from records available in the byre section of the farm. Initially all data were recorded on a day-to-day basis and were then tabulated on a master sheet on a week-by week and month-by-month basis to assess weekly, monthly, and yearly variations.

Data on causes of mortality: Data on the causes of mortality were obtained from death reports routinely prepared by veterinarians at the Veterinary Hospital of the CCBDF. Each death report usually consisted of history, clinical and macroscopic post-mortem findings, and occasionally laboratory data. However, because most diagnoses were based on clinical grounds and post-mortem findings and in such cases confirmed by laboratory aids, the data were arranged into five major diagnostic groups as bacterial and mycobacterial diseases; viral disease; protozoan disease; disease syndrome and physiological disorder. The data were checked manually for obvious inconsistencies, recording errors, or missing data.

Statistical analysis: Microsoft Excel 2003 was used to calculate the descriptive statistics. Then the collected data were transferred to STATA version 11 (Stata Corporation, Texas, USA, 2009) for statistical analysis. The Poisson regression model was used to analyze the mortality of dairy cattle. All tests of statistical significance were carried out at the $\mathrm{p}<0.05$ level unless otherwise stated.

\section{Results}

A total 1759 animals died during the 16 years (1992-2007) that were evaluated. Among them, female cattle died more than males and the average overall mortality rate was $5.60 \%$. The estimated annual mortality rates and pattern of dairy cattle are illustrated in Figure-1. Trends in mortality indicated that the highest number of dairy cattle died in 2004 which accounted for 215 (11.58\%) deaths. This was approximately twice the number of deaths compared with the previous 12 years. There was a lower level of cattle mortality rate (CMR) for the period of 1992 to 1999 (in those 8 years CMR varied between $1.05 \%$ and $6.07 \%$ ) and a higher rate for the period of 2000 to 2007 during which CMR varied between $1.16 \%$ and $11.58 \%$.

Mortality among dairy cattle was highest up to 365 days of age and in female calves, which accounted for $40.31 \%$ of deaths. The lowest mortality among dairy cattle was estimated in heifers $(5.06 \%)$.

Calves $(71.01 \%)$ had higher mortality rate compared with young $(10.85 \%)$ and adult cattle $(18.13 \%)$. These differences are statistically significant (Table-1). Higher percentage of deaths was observed within 365 days of age and the mortality started to decrease gradually after their first month of life and dropped to a lower rate with the increase of age. This low rate of mortality was maintained during the remaining part of one year of age with slight variations between different age intervals (Table-2).

The highest number of cattle deaths was in the Local $\times$ Friesian herd category $(52.70 \%)$ followed by Sindhi $\times$ Friesian (15.97), Australian $\times$ Friesian $\times$ Sahiwal (8.64), Local $\times$ Sindhi $\times$ Friesian $(8.07)$, Local 
Table-1: Descriptive statistics and Poisson regression analysis by age of dairy cattle mortality on the CCBDF, Savar, Bangladesh (1992-2007).

\begin{tabular}{|c|c|c|c|c|}
\hline \multirow{2}{*}{$\frac{\text { Category of animal }}{\text { Female calves } \leq 365 \text { days }}$} & \multirow{2}{*}{$\frac{\text { Number of deaths }}{709}$} & \multirow{2}{*}{$\frac{\text { P-value }^{\text {a }}}{0.000}$} & \multicolumn{2}{|c|}{$95 \%$ confidence interval $^{a}$} \\
\hline & & & 1.968032 & 2.621291 \\
\hline Male calves $\leq \overline{36} 5$ days & 540 & 0.000 & 1.184095 & 1.559081 \\
\hline Heifers 365 days to $\leq 730$ days & 89 & 0.258 & -0.1605987 & 0.5994834 \\
\hline Young bulls 365 days to $\leq 730$ days & 102 & 0.002 & -0.7171178 & -0.1634381 \\
\hline Bulls $\geq 731$ days & 137 & 0.037 & 0.0324649 & 1.062232 \\
\hline Cows $\geq 731$ days & 182 & 0.000 & 0.6494502 & 1.34968 \\
\hline
\end{tabular}

a Used in Poisson regression.

Table-2: Relationship of calf mortality of different intervals age in CCBDF, Savar, Bangladesh (1992-2007)

\begin{tabular}{|c|c|c|c|c|c|c|}
\hline \multirow[t]{2}{*}{ Age (days) } & \multicolumn{3}{|c|}{ No. of deaths } & \multicolumn{3}{|c|}{ Mortality (\%) } \\
\hline & Female & Male & Total & Female & Male & Total \\
\hline $1-30$ & 204 & 168 & 372 & 28.77 & 31.11 & 59.88 \\
\hline $31-60$ & 157 & 118 & 275 & 22.14 & 21.85 & 43.99 \\
\hline $61-90$ & 101 & 68 & 169 & 14.25 & 12.59 & 26.84 \\
\hline $91-120$ & 56 & 38 & 94 & 7.90 & 7.04 & 14.94 \\
\hline $121-150$ & 34 & 30 & 64 & 4.80 & 5.56 & 10.36 \\
\hline $151-180$ & 21 & 17 & 38 & 2.96 & 3.15 & 6.11 \\
\hline $181-210$ & 15 & 14 & 29 & 2.12 & 2.59 & 4.71 \\
\hline $211-240$ & 27 & 11 & 38 & 3.81 & 2.04 & 5.85 \\
\hline $241-270$ & 22 & 16 & 38 & 3.10 & 2.96 & 6.06 \\
\hline $271-300$ & 21 & 15 & 36 & 2.96 & 2.78 & 5.74 \\
\hline $301-330$ & 21 & 18 & 39 & 2.96 & 3.33 & 6.29 \\
\hline $331-365$ & 30 & 27 & 57 & 4.23 & 5.00 & 9.23 \\
\hline
\end{tabular}

Table-3: Seasonal mortality (\%) in different breeds of dairy cattle on the CCBDF, Savar, Bangladesh (1992-2007).

\begin{tabular}{|c|c|c|c|c|c|c|c|c|c|}
\hline Season & AFS & AFSF & $F$ & L & LF & LSIF & SIF & SI & Season total \\
\hline Rainy & $8.30(146)$ & $1.88(33)$ & $2.56(45)$ & $3.87(68)$ & $11.43(201)$ & $0.63(11)$ & $0.06(1)$ & $0.28(5)$ & $28.99(510)$ \\
\hline Summer & $0.06(1)$ & $0.40(7)$ & $0.17(3)$ & $0.34(6)$ & $31.67(557)$ & $0.17(3)$ & $0.11(2)$ & $0.11(2)$ & $33.03(581)$ \\
\hline Winter & $0.28(5)$ & $0.40(7)$ & $0.40(7)$ & $0.28(5)$ & $9.61(169)$ & $7.28(128)$ & $15.80(278)$ & $3.92(69)$ & $37.98(668)$ \\
\hline Overall & $8.64(152)$ & $2.67(47)$ & $3.13(55)$ & $4.49(79)$ & $52.70(927)$ & $8.07(142)$ & $15.97(281)$ & $4.32(76)$ & $100.00(1759)$ \\
\hline
\end{tabular}

AFS $=$ Australian $\times$ Friesian $\times$ Sahiwal; AFSF $=$ Australian $\times$ Friesian $\times$ Sahiwal $\times$ Friesian; F = Holstein Friesian; L $=$ Local; LF $=$ Local $\times$ Friesian; LSIF $=$ Local $\times$ Sindhi $\times$ Friesian; SIF $=$ Sindhi $\times$ Friesian; and SI $=$ Sindhi. Values in parentheses indicate the total numbers of cattle that died during each season.

Table-4: Specific diagnosis of diseases and syndromes responsible for dairy cattle mortality on the CCBDF, Savar, Bangladesh (1992-2007).

\begin{tabular}{lcc}
\hline Diseases and syndrome & No. of deaths & $\begin{array}{c}\text { Proportional mortality rate } \\
(\mathbf{n = 1 7 5 9} \text { dead })\end{array}$ \\
\hline Black quarter & 31 & 1.76 \\
Tuberculosis & 362 & 20.58 \\
FMD & 26 & 1.48 \\
Babesiosis & 40 & 2.27 \\
Debility & 78 & 4.43 \\
Enteritis & 274 & 15.58 \\
Internal Haemorrhage & 38 & 2.16 \\
Malnutrition & 104 & 5.91 \\
Pneumonia & 702 & 39.91 \\
Tympanitis & 45 & 2.56 \\
Hairball & 59 & 3.35 \\
\hline
\end{tabular}

(4.49), Sindhi (4.32), Friesian (3.13), and 2.67\% cases of Australian x Friesian $\times$ Sahiwal $\times$ Friesian. Table-3 depicts the seasonal mortality rates among different breeds. The seasonal comparison of mortality rates indicated that the overall mortality rate varied between $28.99 \%$ (rainy season) to $37.98 \%$ (winter season) (Table-3).

A total of 11 types of diseases and disease syndromes responsible for the death of dairy cattle were identified at the CCBDF Veterinary Hospital. The overall mortality rates per disease or disease syndrome is shown in Table-4.

A total of 393 (22.34\%) deaths were estimated to be from bacterial and mycobacterium diseases in which tuberculosis $(20.58 \%)$ and BQ $(1.76 \%)$. Of viral diseases, $26(1.8 \%)$ of total cases were associated with FMD whereby it is higher in female animals $(84.62 \%)$. With regards to protozoal diseases, total of $40(2.27 \%)$ death were from babesiosis and mainly in female animals $(97.50 \%)$ compared to males $(2.50 \%)$. Calves had the greatest mortality accounting for $80.0 \%$ of deaths. Other disease syndrome accounts $55.49 \%$ of all deaths, whereby pneumonia (39.91\%) and enteritis $(15.58 \%)$. Mortality caused by enteritis and pneumonia also showed makeable associations to the age and sex of the animal. Of all deaths, 197 (11.20\%) female 
calves $(<365$ days) died from enteritis, and 238 $(13.53 \%)$ female and $246(13.99 \%)$ male calves were associated with pneumonia. A higher percentage of calves $(74.36 \%)$ died from debility. Malnutrition accounted for $5.91 \%$ of the deaths, and $45(2.56 \%)$ cases of tympanitis were diagnosed by history and post-mortem findings. Physiological disorder (hairball) contributed to $3.35 \%$ of the overall mortality rate, with the highest in female calves (64.41\%) followed by cows $(25.42 \%)$, heifers $(6.78 \%)$, young bulls (1.69\%), and male calves (1.69\%).

\section{Discussion}

Among the deaths, more than two-thirds of mortality occurred within the first year of life with a greater percentage occurring in the first months. These findings are similar to previously reported findings [11-13]. The higher mortality in calves might be due to poor management practices of calves and their increased susceptibility to diseases and environmental stress than older animals as well as inadequate intake of colostrums [14-15]. Although calf mortality on smallholder traditional dairy farms in Bangladesh has been estimated to be relatively lower [16], this estimate is not applicable to the CCBDF since it follows an intensive animal husbandry system which differs markedly from the traditional extensive husbandry systems in villages. Female cattle had higher mortality rates than males, possibly due to the presence of a higher proportion of female animals on the farm. This is likely to reflect their relative value; females give birth to the calves which then join the milking herd and provide a regular income. Similar findings were also reported in a study of mortality pattern in a closed herd of dairy cattle in India [17].

The rate of mortality was higher in crossbred cattle compared with indigenous/local and other breeds available on the CCBDF. The higher mortality rate in crossbred cattle may be explained by the prevailing environmental conditions, including management and climate. Higher mortality in exotic and crossbred cattle could be expected in tropical climates because of greater susceptibility to climatic and disease stresses in such environments. The high rate of mortality in crossbred (Local $\times$ Holstein Friesian) cattle may indicate lower survivability of this breed compared with other breeds under the prevailing conditions of Bangladesh. This observation is in agreement with previous findings of higher mortality in exotic and crossbred cattle [12]. The largest number of cattle died in the winter season followed by the summer and rainy seasons. Higher mortality in crossbred cattle was observed during the summer season compared with local/indigenous and other sub-continent breeds. The trends of this study indicated that local/indigenous breeds had better adaptability for hot humid weather (summer) and higher susceptibility to cold (winter), whereas the opposite trend was seen in crossbreds.

Tuberculosis was found the second most important cause of death in dairy cattle. Bovine tuberculosis (bTB) is a chronic debilitating disease and is a cause of morbidity and mortality in livestock, wildlife and humans [18]. In a confined herd like on the CCBDF, tuberculosis can be controlled and eradicated by following a "detect and discard" policy. Culling to reduce the population density can also decrease transmission of the disease. The death of cattle by BQ was lower compared with other diseases, possibly due to treatment of infected animals and vaccination against the disease. Among the deaths by $\mathrm{BQ}$, a higher proportion was observed in calves within first year of life. Similarly, Sultana et al. [19] reported that animals up to 12 months of age have a 6.66 times higher probability of mortality than animals over 12 months of age.

The capability of rapidly diagnosing the disease and identifying its causative agent is critical to combat diseases and halt epidemics [20]. Recent technological developments have led to the proliferation of new, rapid diagnostic tests that hold promise for the improved management and control of infectious diseases. Mycobacterial infections such as tuberculosis (TB), bovine tuberculosis (bTB), and Johne's disease (JD) are major infectious diseases of both human and animals [21]. For TB and bTB, there has been recent progress in developing laboratory-free diagnostic methods. New technologies such as microfluidics [22] and "Lab-on- Chip" [23] are examples of promising new technologies that can underpin development of laboratory-free diagnostic devices for these mycobacterial infections [21]. Although there have been developed a sensitive serum ELISA test, ethanolvortex enzyme-linked immunosorbent assay (EVELISA), using ethanol extract of Mycobacterium avium ssp. Paratuberculosis (MAP) especially for Johne's disease [24]. Another study was conducted to assess the performance of EVELISA optimized to diagnose bTB using serum samples from various groups of red deer (Cervus elaphus) including animals experimentally infected with $M$. bovis or MAP and suggests that EVELISA can form a basis for development of a sensitive and specific test for bTB in deer [25]. Furthermore, EVELISA-based control measures increase the annual per capita revenue of US dairy farms when compared to no JD control and ELISAbased JD control, respectively [26]. An AC electrokinetic impedance sensing can be used for rapid and sensitive detection of specific antibodies in serum samples and this could be a basis for development of a point of care diagnostic device for human and bovine tuberculosis [27].

Death by FMD showed marked age-specificity, with calves having the highest proportion of deaths. It should be pointed out that in a previous study; FMD was shown to contribute significantly to calf mortality even after regular vaccination [12]. This study demonstrated that FMD could be controlled and no further cases were reported after a certain period of 
time. It would, therefore, be worthwhile to improve management policies including destruction of infected beddings, regular use of disinfectants, separation of uninfected animals from infected ones, and the quality of vaccines used. Protozoan disease mortality of cattle from babesiosis was found to be higher in calves. This finding is congruent with previous findings showing that babesiosis is prevalent in calves and only calves $(2.0 \%)$ died from babesiosis among the group of dairy cattle [17].

The most important disease syndrome leading to deaths was pneumonia and a higher prevalence of this disease was found in calves compared with adults. Similarly, other studies [28] also reported a higher proportion of calves dying from pneumonia. Younger age, inadequate housing for newborn calves, climatic change, and lack of care might contribute to the prevalence of pneumonia among calves. Enteritis is of particular importance as a significant number of cattle died from this syndrome. This result agreed with the findings of others [29-30] where they reported that the digestive problems are primary causes of mortality in cattle. Among them, calves were more common than other categories of animals. Calves are more dependent on milk, milk replacer, and are incapable of digesting all kinds of food materials. Overfeeding, sudden change in diet, poor hygienic condition of feeding utensils, and calf barns might be the cause of death from enteritis. Pneumonia and enteritis are multifactorial diseases that are closely associated with each other [12]. It has been suggested that common factors related to either management techniques or specific agents predispose calves to both syndromes. Deaths caused by malnutrition were also more common in female calves. Alternatively, a previous study [31] reported that mortality caused by malnutrition is more common in male calves. On the CCBDF it is not uncommon to find emaciated and neglected calves. Particularly when the feed supply is not always adequate for all animals or an incorrect proportion of feed ingredients is given to the animals. Debility was also high in female calves. Lack of vegetation, unsuitable and insufficient food, and the prevalence of other diseases might be the cause of debility. The majority of cattle that died from hairballs were calves, but a few cases of cows and heifers were also found. Hairballs in calves might originate from ingestion of hair during periods of excessive licking, and in adult animals is usually caused by itchy skin conditions. Ingestion of hair is usually associated with persistent suckling of pen mates. Other studies [32] also reported on the mortality of cattle from hairballs.

\section{Conclusions}

Age of the animal was found to be the most important risk factors of mortality followed by breed and season. So, this study suggested that greater attention should be paid to the time of colostrum feeding, proper timing and management of calves, and hygiene of calf barns. Because of the complex nature of dairy management systems, a variety of causes are responsible for diseases and mortality of dairy cattle.

\section{Authors' contributions}

This is the epidemiological study of master's research work of MMH. AHMK and AKMAR designed and supervised the work. Implementation of the study design and data recording was done by MMH. HSC and MMH critically analyzed the data and revised the manuscript. The manuscript reviewed and drafted by $\mathrm{MMH}$ and MSI. All authors read and approved the final manuscript.

\section{Acknowledgements}

The authors are thankful to the farm authorities and all the respondent staffs who cooperated during the period of data collection. Special thanks goes to Dr. Ibrahim Hossain, farm manager and the authors also grateful to Chief Veterinary Officer, Veterinary Hospital, CCBDF. This study was financially supported by the Directorate-General for Development Cooperation (DGDC), Belgium.

\section{Competing interests}

The authors declare that they have no competing interests.

\section{References}

1. Maia, R. P., Ask, B., Madsen, P., Pedersen, J. and Labouriau, R. (2014) Genetic determination of mortality rate in Danish dairy cows: A multivariate competing risk analysis based on the number of survived lactations. J. Dairy Sci., 97: 1753-1761.

2. Garry, F. (2009) How big of a problem is adult cow mortality? Western Dairy News 9: W-31-W-32.

3. Maher, P., Good, M. and More, S. J. (2008) Trends in cow numbers and culling rate in the Irish cattle population, 2003 to 2006. Irish Vet. J., 61:455-463.

4. Shaikh, S. R. (2009) Estimation and analysis of morbidity and mortality in cattle under village condition of Maharashtra. M.V.Sc. Thesis submitted to Indian Veterinary Research Institute, Izatnagar, Uttar Pradesh.

5. Thomsen, P.T., Kjeldsen, A. M., Sorensen, J. T., Houe H. and Ersboll A. K. (2006) Herd-level risk factors for the mortality of cows in Danish dairy herds. Vet. Rec., 158: 622-626.

6. Thomsen, P. T. and Sørensen, J. T. (2009) Factors affecting the risk of euthanasia for cows in Danish dairy herds. Vet. Rec., 165:43-45.

7. Alvåsen, K., Jansson Mörk, M., Hallén Sandgren, C., Thomsen, P. T. and Emanuelson, U. (2012) Herd-level risk factors associated with cow mortality in Swedish dairy herds. J. Dairy Sci., 95:4352-4362.

8. Prasad, S, Ramachandran, N. and Raju, S. (2004) Mortality patterns in dairy animals under organized herd management conditions at Karnal, India. Trop. Anim. Health Prod., 36: 645-654.

9. Thomsen, P.T., Kjeldsen, A. M., Sorensen, J. T. and Houe, H. (2004) Mortality (including euthanasia) among Danish dairy cows (1990-2001). Prev. Vet. Med., 62: 19-33.

10. Islam, S. K. M. A., Hoque, M. A., Alam, M. R., Hassan, M. M. and Rahman, M. A. (2006) A Cross- sectional study on production performance of stall fed dairy cattle at Central cattle Breeding Station (CCBS), Savar, Dhaka, Bangladesh. Bangl. J. Vet. Med., 4: 61-63.

11. Islam, S.S., Ahmed, A. R., Ashraf, A., Khanom, N. and Ahmed, M. B. (2005) Causes and Consequences of Calf Mortality in a Dairy Farm of Bangladesh. J. Anim. Vet. Adv., 4: $260-264$. 
12. Debnath, N.C., Taimura, M. J. F. A., Sahaa, A. K., Ersaduzaman, M., Helaluddin, M., Rahman, M. L., Roy, D. K. and Islam, M. A. (1995) A retrospective study of calf losses on the central dairy cattle breeding station in Bangladesh. Prev. Vet. Med., 24: 43-53.

13. Bangar, Y., Khan, T. A., Dohare, A. K., Kolekar , D. V., Wakchaure, N. and Singh B. (2013) Analysis of morbidity and mortality rate in cattle in village areas of Pune division in the Maharashtra state. Vet World., 6(8):512-515.

14. Brenner, J., V. Orgad, Burd P. and Gat Z. (1989) The influence of climate on the mortality of young calves in two farming systems in Israel. Israel J. Vet. Med., 45: 32-42.

15. Duguma, B., Kechero, Y. and Janssens, G. P. J. (2012) Survey of Major Diseases Affecting Dairy Cattle in Jimma Town, Oromia, Ethiopia. Global Veterinaria, 8: 62-66.

16. Debnath, N.C., Sil, B. K., Selim, S. A., Prodhan, M. A. M. and Howlader, M. M. R. (1990) A retrospective study of calf mortality and morbidity on smallholder traditional farms in Bangladesh. Prev. Vet. Med., 9: 1-7.

17. Somavanshi, R. (1995) Mortality pattern in a closed herd of dairy cattle in sub-temperate hilly region. Indian Vet J., 72: 528-530.

18. Humblet, M. F., Boschiroli, M. L. and Saegerman, C. (2009): Classification of worldwide bovine tuberculosis risk factors in cattle: a stratified approach. Vet. Res., 40:50.

19. Sultana, M., Ahad, A., Biswas, P. K., Rahman, M. A. and Barua, H. (2008) Black Quarter (BQ) Disease in Cattle and Diagnosis of BQ Septicaemia Based on Gross Lesions and Microscopic Examination. Bangl. J Microbiol., 25: 13-16.

20. Li, S., Cui, H., Yuan, Q., Wu, J., Wadhwa, A., Eda, S. and Jiang, H. (2014) AC electrokinetics-enhanced capacitive immunosensor for point-of-care serodiagnosis of infectious diseases. Biosens. Bioelectron., 51: 437-443.

21. Wadhwa, A., Hickling, G. J. and Eda, S. (2012) Opportunities for improved serodiagnosis of human tuberculosis, bovine tuberculosis, and paratuberculosis. Vet. Med. Int., 2012:1-13.

22. Wadhwa, A., Foote, R. S., Shaw, R. W. and Eda, S. (2012) Bead-based microfluidic immunoassay for diagnosis of
Johne's disease. J. Immunol. Methods., 382: 196-202.

23. Liu, X., Yang, K., Wadhwa, A., Eda, S., Li, S. and Wu, J. (2011) Development of an AC electrokinetics-based immunoassay system for on-site serodiagnosis of infectious diseases. Sensor Actuat A-Phys., 171:406-413.

24. Wadhwa, A., Bannantine, J. P., Byrem, T. M., Stein, T. L., Saxton, A. M., Speer, C. A. and Eda, S. (2012) Optimization of serum EVELISA for milk testing of Johne's disease. Foodborne Pathog. Dis., 9: 749-754.

25. Wadhwa, A., Johnson, R. E., Mackintosh, C. G., Griffin, J. F., Waters, W. R., Bannantine, J. P. and Eda, S. (2013) Use of ethanol extract of Mycobacterium bovis for detection of specific antibodies in sera of farmed red deer (Cervus elaphus) with bovine tuberculosis. BMC Vet Res., 9: 256.

26. Massaro, T., Lenhart, S., Spence, M., drakes, C., Yang, G., Agusto, F., Johnson, R., Whitlock, B., Wadhwa, A. and Eda, S. (2013) Modeling for cost analysis of johne's disease control based on EVELISA testing. J. Biol. Syst., 21(4).

27. Cui, H., Li, S., Yuan, Q., Wadhwa, A., Eda, S., Chambers, M., Ashford, R., Jiang, H. and Wu, J. (2013) An AC electrokinetic impedance immunosensor for rapid detection of tuberculosis. Analyst., 138:7188-7196.

28. Bhuller, M. S. and Tiwana M. S. (1985) Factors affecting mortality among buffalo calves. Indian J. Anim. Sci., 55: 599-601.

29. Malik, S., Verma, A., Kumar, A., Gupta, M.K. and Sharma, S. D. (2012) Incidence of calf diarrhea in cattle and buffalo calves in Uttar Pradesh, India. Asian J. Anim. Vet. Adv., 7:1049-1054.

30. Megersa, B., Yacob, A., Regassa, A., Abuna, F., Asmare, K. and Amenu, K. (2009) Prevalence and incidence rates of calf morbidity and mo rtality and associated risk factors in crossbred calves. Ethiopian Vet. J., 13: 59-68.

31. Mulei, C.M., Gitau, G. K. and Mbuthia, P.G. (1995) Causes of calf mortality in Kabete area of Kenya. Onderstepoort $J$. Vet. Res., 62: 181-185.

32. Abutarbush, S. M. and Naylor, J. M. (2006) Obstruction of small intestine by a trichobezoar in cattle: 15 cases (19922002).J.Am. Vet. Med.Assoc., 229: 1627-1630. 